\title{
Gıdalardan biyoaktif bileşiklerin ekstraksiyonunda derin ötektik çözücülerin kullanımı
}

\section{Utilization of deep eutectic solvents in the extraction of bioactive compounds from food materials}

\author{
Naciye Kutlu ${ }^{1}{ }^{*}(\mathbb{D})$, Merve Sılanur Yılmaz ${ }^{(D)}$, Aslı İşci $^{3}$, Özge Şakıyan ${ }^{4}$ \\ ${ }^{1}$ Bayburt Üniversitesi, Glda İşleme Bölümü, 69500, Bayburt, Türkiye \\ 2,3,4 Ankara Üniversitesi, Gida Mühendisliği Bölümü, 06830, Ankara, Türkiye
}

\begin{abstract}
Özet
Çevre bilincinin her geçen gün artmasıyla, son yıllarda yeşil teknoloji kavramı daha da önem kazanmıștır. Bu kapsamda, tehlikeli maddelerin üretiminin ve tüketiminin azaltılması, harcanan enerji miktarının indirgenmesi ve yenilenebilir kaynakların kullanımının arttırılması amaçlanmaktadır. Gıda, kimya ve ilaç endüstrisinde yaygın olarak kullanılan geleneksel çözücüler yerine, sağllğa zararı olmayan ve yüksek ekstraksiyon verimine sahip çözücülerin kullanımı önerilmektedir. Yeşil çözücüler, toksik olmayan, geri dönüşümü mümkün olabilen, uçucu olmayan ve sentezi için yüksek maliyet gerektirmeyen çözücülerdir. Su, iyonik sıvılar veya süperkritik akışkanlar en çok kullanılan yeşil çözücülerdendir. Son yıllarda bu çözücülerin yanı sıra, derin ötektik çözücüler bu alanda kendine yer bulmuştur. Derin ötektik çözücülerin fiziksel özellikleri iyonik sıvılara benzer olsa da, kimyasal özellikleri farklıdır. Son yıllarda, derin ötektik çözücüler, gıda materyallerinden biyoaktif bileşiklerin (fenolik bileşik, antosiyanin vb.) ekstraksiyonunda yaygın olarak kullanılmaktadır. Bu çözücüler ile ekstraksiyon veriminde önemli ölçüde artış tespit edilmiş̧ir. $\mathrm{Bu}$ derleme, gıdalardan biyoaktif bileşiklerin derin ötektik çözücülerle ekstraksiyonu hakkında çalışmaları irdelemektedir.
\end{abstract}

Anahtar kelimeler: Yeşil teknoloji, Yeşil çözücüler, Derin ötektik çözücüler, Ekstraksiyon, Biyoaktif bileşikler.

\section{Yeşil teknoloji ve çözücüler}

Yeşil teknolojiler, tehlikeli maddelerin üretimini ve tüketimini azaltmayı, tehlikeli kimyasal üretiminde harcanan enerji miktarını indirgemeyi ve yenilenebilir kaynakların kullanımını arttırmayı amaçlamaktadırlar. Yeşil teknolojiler, Anastas ve Werner tarafindan [1] 1998 yılında yayınlanan 12 temel ilkeye dayanmaktadır;

1. Atık önleme: Atık oluşumu, üretimin başlangıcında öngörülüp önlenmelidir.

2. Güvenlik: Kullanılan teknoloji ile hiçbir toksik madde oluşmamalıdır.

3. Tehlike önleme: Çevre ve insan sağlığı için tehlikesiz ürünlerin üretimi ve kullanımı tasarlanmalıdır.

4. Yenilenebilir hammadde: Kullanılan hammaddeler yenilenebilir özellikte olmalıdır.

\section{Abstract}

As the environmental awareness increases, the concept of green technology has gained more importance in recent years. It aims to reduce the production and consumption of hazardous materials, reduce the amount of energy spent and increase the use of renewable resources. It is recommended to use solvents that have non-toxic and high extraction efficiency instead of traditional solvents that are commonly used in the food, chemical and pharmaceutical industries. Green solvents are non-toxic, recyclable, non-volatile and have minimal cost of synthesis. Water, ionic liquids or supercritical fluids are among the most commonly preferred green solvents. In addition to these solvents, deep eutectic solvents took a part in this field in recent years. Although the physical properties of deep eutectic solvents are similar to ionic liquids, their chemical properties are different. In recent years, deep eutectic solvents have been widely used in the extraction of bioactive compounds (phenolic compound, anthocyanin etc.) from food materials. It has been detected a significant increase in extraction efficiency with these solvents. This article reviews the extraction of bioactive compounds from food materials using deep eutectic solvents.

Keywords: Green chemistry, Green solvents, Deep eutectic solvents, Extraction, Bioactive compound.

5. Katalizör kullanımı: Üretimde israfin önlenip, verimin arttırılabilmesi için katalizör kullanılmalıdır.

6. Türevlerin azaltılması: Gereksiz işlemler daha fazla atık oluşumuna neden olduğu için, mümkün olduğunca azaltılmalidır

7. Atom ekonomisi: Üretimde kullanılacak olan her madde, ürün içinde maksimum seviyede yer almalı, boşa harcanmış atomlardan kaçınılmalıdır.

8. Güvenli çözücü kullanımı: Üretim esnasında minimum miktarda ve en tehlikesiz olan çözücü seçilmelidir.

9. Enerji verimliliği: Üretim, mümkün olduğunca ortam sıcaklığında ve atmosferik basınçta olacak şekilde tasarlanmalıdır.

\footnotetext{
* Sorumlu yazar / Corresponding author, e-posta / e-mail: naciyekutlu@ @ayburt.edu.tr (N. Kutlu)

Geliş / Recieved: 22.05.2020 Kabul / Accepted: 18.01.2021 Yayımlanma / Published: 27.07.2021

doi: 10.28948/ngumuh.740817
} 
10. Bozunma tasarımı: Kullanımı biten kimyasallar ortamda birikmemeli, tehlikesiz maddelere bozunabilecek şekilde tasarlanmalıdır.

11. Gerçek zamanlı kontrol: İstenmeyen ürünlerin oluşmaması ya da ortadan kaldırılması için reaksiyonlar gerçek zamanlı gözlenmelidir.

12. Minimum kaza olasılığı: Üretimde kullanılan kimyasallar kaza risklerini en aza indirecek şekilde seçilmelidir.

Yeni geliştirilen teknolojiler, her zaman bu 12 ilkenin tamamını içermese de, bu ilkeler temel alınarak teknolojilerin çevresel etkileri konusunda fikir sahibi olunabilmektedir. Örneğin, ilkelerden biri olan atık önleme, sıklıkla teknolojilerin ne kadar "yeşil" olduğunun ölçüsü olarak kullanılmakta ve üretilen atı miktarı ölçülebilmektedir. Atık kütlesinin, ürünün kütlesine oranı "E-faktör" (environmental factor) olarak tanımlanmakta ve mümkün olan minimum değer alması hedeflenmektedir. Tamamen yeşil teknolojilerde E-faktör değeri sıfırdır [2].

Çözücüler, özellikle kimya sanayii bașta olmak üzere, tekstil, kağıt, gıda, biyokütle, farmakoloji gibi bir çok endüstri kolunda, sıklıkla kullanılmaktadır. Laboratuvar ölçekli çalışmalara bakıldığında ise, sentez, purifikasyon, ekstraksiyon gibi proseslerde kullanım alanı bulmaktadırlar. Sıvıların çözücü olarak kullanımı için, bazı özellikleri sağlamaları gerekmektedir. Örneğin, çalışılan ortam sıcaklıklarında ve basınçlarında, sıvı fazda olabilmeli, ticari saflıkta bulunabilmeli ya da saflaştırılabilmesi kolay ve ucuz olmalıdır [3].

Yeşil çözücüler, toksik olmayan, geri dönüşümü mümkün olabilen, uçucu olmayan ve sentezi için yüksek maliyet gerektirmeyen çözücülerdir. Sürdürülebilir döngü için, kullanılan zararlı çözücülerin yerine, yeşil çözücü kullanımı desteklenmelidir. Sıklıkla kullanılan yeşil çözücülerin sınıflandırılması Şekil 1'de gösterilmiştir [4].

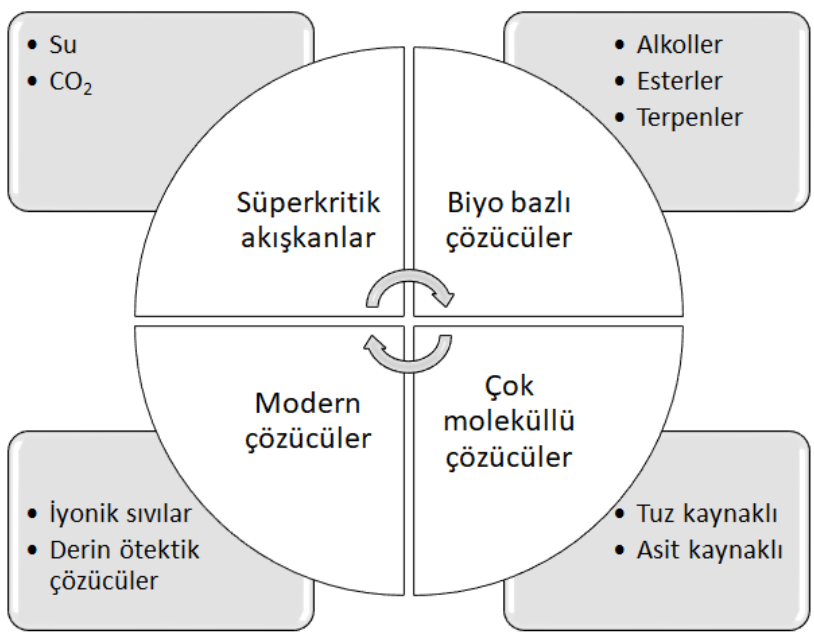

Şekil 1. Sıklıkla kullanılan yeşil çözücüler [4]

$\mathrm{Su}$, saflaştırılması kolay, ucuz, geri dönüşümlü, toksik ve yanıcı olmayan, çevre dostu olduğundan dolayı, birçok alanda yaygın olarak kullanılan bir çözücüdür. Fakat bunun yanı sıra su, birçok gaz ve endüstriyel polimer gibi katılar için zayıf çözücü özelliktedir. Bazı asitler ile reaktif özellik gösterebilmekte, bu durumlarda ise farklı çözücü arayışlarına gidilmektedir [3]. Alternatif olarak kullanılabilen organik çözücülerin çözme kabiliyetleri oldukça yüksek olsa da, bu bileşiklerin pahalı, nispeten daha toksik, yanıcı ve çevreye zararlı oluşları kullanımlarını kısıtlamaktadır [5]. Süperkritik çözücüler (özellikle süperkritik su), laboratuvar ölçekli çalışmalarda uygun olmak ile birlikte, büyük ölçekli çalışmalarda enerji maliyetinden (yüksek basınç ve sıcaklık) dolayı tercih edilmemektedir [3, 6, 7]. İyonik çözücüler, oda sıcaklığında sıvı fazda olan organik tuzlardır. İyonik sıvılar arasında, 1alkil-3-metilimidazolium bazlı olanlar çok kullanılmakta ve genellikle klor $(\mathrm{Cl})$ ve brom $(\mathrm{Br})$ iyonları ile birleştirilmektedirler [8]. Fakat iyonik sıvıların, yüksek maliyetleri ve toksisite çalışmalarının yetersiz olması nedeniyle kullanımları sınırlandırılmıștır [9, 10]. Derin ötektik çözücüler bu sorunları en aza indirebilmek için geliştirilmiş yeni nesil yeşil çözücülerdendir [9].

$\mathrm{Bu}$ derlemenin amacı, gida materyallerinden biyoaktif bileşiklerin (fenolik bileşik, antosiyanin vb.) ekstraksiyonunda derin ötektik çözücüleri kullanan araştırmaları özetlemektir. Bu bağlamda, bu makale ile derin ötektik çözücüler hakkında temel bilginin yanı sıra, derin ötektik çözücü ekstraksiyon prensibi, derin ötektik çözücülerin ekstraksiyona etkisi ve yaşanılan zorluklar hakkında bilgi verilmektedir.

\section{Derin ötektik çözücüler}

Faz diyagramında, iki ya da daha fazla bileşiğin karıșması sırasında, bu karıșımı oluşturan bileşiklerin erime noktalarından daha düşük değere sahip olan bir karışım oluşabilmektedir. Bu karışımın oluştuğu nokta, ötektik nokta ve oluşan karışım da derin ötektik çözücü olarak adlandırılmaktadır. Derin ötektik çözücü formülasyonu genel olarak ikili karışımlardan oluşmaktadır. Bileşenlerden biri hidrojen bağı alıcısı (HBA), diğeri ise bir hidrojen bağı donörüdür (HBD). Derin ötektik çözücü oluşumunda, bileşikler arasında kovalent bağ değil, hidrojen bağı meydana gelmektedir. Ötektiği oluşturan hidrojen bağı alıcısı ve hidrojen bağı donörü arasındaki oran, bileşenlerin karşılıklı hidrojen bağlama yeteneklerine bağlıdır [3]. Derin ötektik çözücülerin fiziksel özellikleri iyonik sıvılara benzer olsa da, kimyasal özellikleri farklıdır [9].

Derin ötektik çözücüler, yapılarını oluşturan bileşikler baz alındığında 4 kategori altında toplanmaktadırlar. Bir kuarterner amonyum tuzu ve bir metal klorür (kategori 1), bir kuarterner amonyum tuzu ve bir metal klorür hidrat (kategori 2), bir kuarterner amonyum tuzu ve bir hidrojen bağı donörü (HBD) (kategori 3), son olarak da bir hidrojen bağı donörü ve bir metal klorürden (kategori 4) oluşabilmektedir. Hızlı ve kolay hazırlanabilmesi, su ile reaktiflik göstermemesinden dolayı, derin ötektik çözücü oluştururken en çok kategori 3 kullanılmaktadır. En çok kullanılan derin ötektik çözücü türü ise, hidrojen bağ 1 donörü olarak işlev gören amin, alkol, asit ve şeker gibi farklı kimyasal fonksiyonel gruplarla karıştırılan, hidrojen bağ alıcısı (HBA) kolin klorürden $(\mathrm{ChCl})$ oluşmaktadır. Kolin klorür hem kuaterner amonyum tuzu hem de alkol içeren iki işlevli organik bir bileşiktir. Suda çözünebilen ve B grubu 
vitaminler sınıfında tanımlanan Kolin, ayrıca göreceli olarak düşük maliyetlidir [11].

Derin ötektik çözücülerin avantajlarından bazıları, sentezinin daha kolay, daha kararlı, biyobozunur ve düşük toksisite değerlerine sahip olmalarıdır. $\mathrm{Bu}$ özellikler sebebiyle, ekstraksiyon proseslerinde s1klıkla tercih edilmeye başlanmıştır [12,13]. Derin ötektik çözücülerin diğer bir özelliği de, erime noktasının, kendini oluşturan her bir bileşiğin erime noktasından daha düşük olmasıdır. Örneğin, hidrojen bağ alıcı özellikte olan $\mathrm{ChCl}$ bileşiğinin erime noktas $302{ }^{\circ} \mathrm{C}$ ve hidrojen bağ donörü özellikte olan ürenin erime noktası $133^{\circ} \mathrm{C}$ iken, bu bileșikler ile oluşturulan ötektik çözücünün (ChCl:üre, mol oranı 1:2) erime noktası $12{ }^{\circ} \mathrm{C}$ 'dir [14]. Bazı derin ötektik çözücülerin erime noktaları Tablo 1'de verilmiştir. Genel olarak, çoğu ötektik çözücü oda sıcaklığında sıvı formdadır [3]. Bu özelliği, oda sıcaklığında farklı proseslerde rahatlıkla kullanımına olanak sağlamaktadır.

Tablo 1. Bazı derin ötektik çözücülerin erime noktaları

\begin{tabular}{|c|c|c|c|c|}
\hline HBA & HBD & $\begin{array}{c}\text { Mol } \\
\text { oran1 }\end{array}$ & $\begin{array}{c}\text { Erime noktas } 1 \\
\left({ }^{\circ} \mathrm{C}\right)\end{array}$ & Kaynak \\
\hline \multirow{6}{*}{ Kolin klorür } & Laktik asit & $1: 2$ & -78 & [15] \\
\hline & Okzalit asit & $1: 1$ & -40 & [16] \\
\hline & Malik asit & $1: 1$ & -56 & [15] \\
\hline & Gliserol & $1: 2$ & -40 & [17] \\
\hline & Fruktoz & $2: 1$ & 10 & [16] \\
\hline & Glukoz & $2: 1$ & 15 & [16] \\
\hline \multirow{2}{*}{ Kolin asetat } & Üre & $1: 2$ & 18 & [18] \\
\hline & Gliserol & $1: 1,5$ & 13 & [19] \\
\hline Kolin bromür & $\begin{array}{l}\text { Levülinik } \\
\text { asit }\end{array}$ & $1: 4$ & 10,7 & [18] \\
\hline Kolin florür & Üre & $1: 2$ & 1 & [18] \\
\hline Kolin nitrat & Üre & $1: 2$ & 4 & [18] \\
\hline \multirow{5}{*}{$\begin{array}{l}\text { Asetilkolin } \\
\text { klorür }\end{array}$} & Üre & $1: 2$ & -14 & [18] \\
\hline & Ksiloz & $1: 1$ & -30 & [20] \\
\hline & Glikoz & $1: 1$ & -7 & [20] \\
\hline & Mannoz & $1: 1$ & -16 & [20] \\
\hline & Fruktoz & $1: 1$ & -47 & [20] \\
\hline
\end{tabular}

\section{Derin ötektik çözücülerin ekstraksiyonda kullanımı}

Bitkilerde bulunan fenolik bileşikler, insan sağlığına olan pozitif etkilerinden (anktioksidan, antimutajenik, antimikrobiyal ve anti-kanserojen) dolayı önem arz etmektedir [21, 22]. Gıda materyallerinden biyoaktif bileşik ekstraksiyonu için, yüksek miktarlarda organik çözücü kullanımı ve uzun ekstraksiyon süreleri gerekmektedir [23]. Günümüzde ekstraksiyon işlemi için yaygın olarak kullanılan geleneksel organik çözücülere örnek olarak metanol, kloroform, hekzan ve etil asetat verilebilir. Ancak, bu uçucu ve tehlikeli organik çözücülerin fazla tüketimi, çevreye zarar vermekte ve ekstraktlarda kalıntı bırakarak toksik etki gösterebilmektedir [24]. Bu sebeple, son yıllarda yeni nesil çözücüler sıklıkla tercih edilmektedir. Son dönemdeki çalışmalar, derin ötektik çözücüler kullanılarak yapılan ekstraksiyon işleminde, kuersetin, antisiyoninler ve kateşinler gibi bazı biyoaktif bileşiklerin yüksek verim ile elde edilebildiğini göstermiştir [25].

Ekstraksiyon işleminde derin ötektik çözücülerin kullanılmasının başlıca nedeni olarak, yüksek çözme kabiliyetleri, yani moleküller arasında hidrojen bağı oluşumunu kolaylaştıran proton ve elektron alma/verme kabiliyetleri gösterilebilmektedir. Bunun yanında, derin ötektik çözücülerin viskozite ve polariteleri gibi ayarlanabilir fizikokimyasal özellikleri de ekstraksiyon sürecinde önem arz etmektedir. Örneğin, derin ötektik çözücülerin polaritesi polar veya polar olmayan olarak ayarlanabilir, bu da onların çeşitli doğal bileşik gruplarının ekstraksiyonu için etkili bir çözücü yapmaktadır [26, 27].

Son y1llarda derin ötektik çözücülerin biyoaktif bileşik ekstraksiyonları ile ilgili yapılan çalıșmalar incelenmiş ve Tablo 2'de özetlenmiştir. Tablo incelendiğinde, HBA olarak genellikle kolin klorürün kullanıldığı, ancak bunun yanında sitrik asit, betain, glikoz ve L-prolin gibi farklı HBA'ların da kullanıldığ 1 görülmektedir. HBD olarak ise genellikle alkol ve organik asitler tercih edilmektedir. Toksik ve aşındırıcı olmayan, polar yapılardaki alkol bazlı derin ötektik çözücülerin birçok organik ve inorganik bileşik ekstraksiyonunda başarıyla uygulandı ğ bildirilmiştir [28].

Ekstraksiyon verimi, çözünen ve çözücü arasında bağlanma (esas olarak hidrojen bağı) oluşumu ile belirlenmektedir. Örneğin, bitkilerin hücre duvarında bulunan bazı selüloz veya ligninler, biyoaktif bileşiklerin çözücülere salınmasını hızlandıran hidrojen bağlanma etkileşimleri nedeniyle derin ötektik çözücülerde çözülebilir $[39,40]$. Derin ötektik çözücüler ile ilgili yapılan çalışmalar, bu çözücülerin yüksek 1sıl stabilitesi, düşük 1sıl iletkenlik ve düşük uçuculuk gibi özelliklere sahip olduğunu göstermiştir. Bunun yanında son yapılan çalışmalarda, hidrofobik özelliğe sahip derin ötektik çözücüler oluşturulmuştur. Bu derin ötektik çözücüler, sulu çözeltilerden apolar molekülleri ekstrakte etme kabiliyetleri sayesinde ekstraksiyon verimliliğini arttırmaktadır [12, 41]. Meng vd. [25], Pollen Typhae bitkisinden flavonoidlerin ekstraksiyonunu, geleneksel çözücüler (etanol, su, metanol ve \%75'lik etanol çözeltisi) ile kolin klorür:1,2 propandiol (1:4) bileşiklerinden oluşan derin ötektik çözücü kullanarak gerçekleştirmişlerdir. Derin ötektik çözücü ile yapılan ekstraksiyon işleminin daha avantajlı olduğunu bildirmişlerdir. Bosilijkov vd. [42], şarap tortusundan toplam antosiyonin ekstraksiyonu yapmışlardır. Derin ötektik çözücü olarak, kolin klorür:malik asit çözeltisi kullanılırken, geleneksel çözücü olarak etanolün asitlendirilmiş sulu çözeltisini kullanmışlardır. Çalışma sonucunda, derin ötektik çözücü ile yapılan ekstraksiyon veriminin daha yüksek olduğu görülmüştür. Literatür incelendiğinde, derin ötektik çözücü ile yapılan ekstraksiyon çalışmalarında çözünürlük, difüzyon ve viskozite üzerine etkilerinden dolayı sicaklık önemli bir parametre olarak görülmüştür [33, 35, 43]. Zhou vd. [44], yapmış oldukları çalışmada, beyaz dut yapraklarından ultrason destekli ekstraksiyon ile fenolik maddeleri ekstrakte etmiştir. Derin ötektik çözücü olarak, kolin klorür ve sitrik asit karışımının kullanıldığı ekstraksiyon işlemi farklı sıcaklıklarda (30, 40, 50 ve $60{ }^{\circ} \mathrm{C}$ ) yapılmıştır. Ekstraksiyon veriminin, sıcaklığın 
Tablo 2. Derin ötektik çözücüler ile yapılmış ekstraksiyon alanındaki çalışmalar

\begin{tabular}{|c|c|c|c|c|c|c|}
\hline Örnek & HBA & HBD & $\begin{array}{c}\text { Mol } \\
\text { oran1 }\end{array}$ & Ekstraksiyon yöntemi & $\begin{array}{l}\text { Ekstrakte edilen } \\
\text { bileşik }\end{array}$ & Kaynak \\
\hline Karabuğday Lahanası & \multirow{21}{*}{$\begin{array}{l}\text { Kolin } \\
\text { klorür }\end{array}$} & $\begin{array}{l}\text { Trietilen } \\
\text { glikol }\end{array}$ & $1: 4$ & $\mathrm{UDE}^{*}\left(40^{\circ} \mathrm{C}, 40 \mathrm{dk} ., 40 \mathrm{kHz}, 700 \mathrm{~W}\right)$ & Flavonoidler & {$[29]$} \\
\hline Karabuğday Lahanası & & $\begin{array}{c}1,2 \\
\text { Propandiol }\end{array}$ & $1: 1$ & $\operatorname{UDE}\left(40^{\circ} \mathrm{C}, 40 \mathrm{dk} ., 40 \mathrm{kHz}, 700 \mathrm{~W}\right)$ & Flavonoidler & [29] \\
\hline Karabuğday Lahanası & & 1,4 Bütandiol & $1: 3$ & UDE $\left(40^{\circ} \mathrm{C}, 40 \mathrm{dk} ., 40 \mathrm{kHz}, 700 \mathrm{~W}\right)$ & Flavonoidler & {$[29]$} \\
\hline Karabuğday Lahanası & & Etilen glikol & $1: 2$ & UDE $\left(40{ }^{\circ} \mathrm{C}, 40 \mathrm{dk} ., 40 \mathrm{kHz}, 700 \mathrm{~W}\right)$ & Flavonoidler & [29] \\
\hline Sizma zeytinyağı & & Ksilitol & $2: 1$ & $\mathrm{GE}^{*}\left(40^{\circ} \mathrm{C}, 1 \mathrm{sa}.\right)$ & Fenolik Bileşik & {$[30]$} \\
\hline Üzüm kabuğu & & Oksalik asit & $1: 1$ & $\begin{array}{l}\operatorname{MDE}^{*}\left(50-90^{\circ} \mathrm{C}, 15-90 \mathrm{dk} ., 100 \mathrm{~W}\right) \\
\operatorname{UDE}\left(30-90^{\circ} \mathrm{C}, 15-90 \mathrm{dk} ., 35 \mathrm{kHz}\right)\end{array}$ & Fenolik Bileşik & {$[27]$} \\
\hline Japon hanımeli & & 1,3 bütandiol & $1: 2$ & $\begin{array}{c}\operatorname{MDE}\left(60^{\circ} \mathrm{C}, 20 \mathrm{dk} ., 700 \mathrm{~W}\right) ; \operatorname{UDE}(60 \\
\left.{ }^{\circ} \mathrm{C}, 45 \mathrm{dk} .\right)\end{array}$ & Fenolik Bileşik & {$[31]$} \\
\hline Japon hanımeli & & 1,4 bütandiol & $1: 2$ & $\begin{array}{c}\operatorname{MDE}\left(60^{\circ} \mathrm{C}, 20 \mathrm{dk} ., 700 \mathrm{~W}\right) ; \operatorname{UDE}(60 \\
\left.{ }^{\circ} \mathrm{C}, 45 \mathrm{dk} .\right)\end{array}$ & Fenolik Bileşik & {$[31]$} \\
\hline Bezelye kökleri & & $\begin{array}{c}1,6 \\
\text { hekzandiol }\end{array}$ & $1: 7$ & $\operatorname{MDE}\left(80^{\circ} \mathrm{C}, 11 \mathrm{dk} ., 600 \mathrm{~W}\right)$ & $\begin{array}{l}\text { Genistin, genistein, } \\
\text { apigenin }\end{array}$ & {$[32]$} \\
\hline Yara otu & & Etilen glikol & $1: 2$ & $\mathrm{GE}\left(80^{\circ} \mathrm{C}, 30 \mathrm{dk}.\right)$ & $\begin{array}{l}\text { Rosmarinik asit ve } \\
\text { salviaflasit }\end{array}$ & {$[33]$} \\
\hline Yara otu & & Gliserol & $1: 2$ & $\mathrm{GE}\left(80^{\circ} \mathrm{C}, 30 \mathrm{dk}.\right)$ & $\begin{array}{l}\text { Rosmarinik asit ve } \\
\text { salviaflasit }\end{array}$ & {$[33]$} \\
\hline Yara otu & & $\begin{array}{l}\text { 1,2 Propilen } \\
\text { glikol }\end{array}$ & $1: 2$ & $\mathrm{GE}\left(80^{\circ} \mathrm{C}, 30 \mathrm{dk}.\right)$ & $\begin{array}{l}\text { Rosmarinik asit ve } \\
\text { salviaflasit }\end{array}$ & {$[33]$} \\
\hline Yara otu & & 1,4 Bütandiol & $1: 2$ & $\mathrm{GE}\left(80^{\circ} \mathrm{C}, 30 \mathrm{dk}.\right)$ & $\begin{array}{l}\text { Rosmarinik asit ve } \\
\text { salviaflasit }\end{array}$ & {$[33]$} \\
\hline Yara otu & & 1,3 Bütandiol & $1: 2$ & $\mathrm{GE}\left(80^{\circ} \mathrm{C}, 30 \mathrm{dk}.\right)$ & $\begin{array}{l}\text { Rosmarinik asit ve } \\
\text { salviaflasit }\end{array}$ & {$[33]$} \\
\hline Yara otu & & 2,3 Bütandiol & $1: 2$ & $\mathrm{GE}\left(80^{\circ} \mathrm{C}, 30 \mathrm{dk}.\right)$ & $\begin{array}{l}\text { Rosmarinik asit ve } \\
\text { salviaflasit }\end{array}$ & {$[33]$} \\
\hline Tatar karabuğdayı & & Gliserol & $1: 1$ & $\mathrm{UDE}\left(40^{\circ} \mathrm{C}, 1\right.$ sa., $\left.200 \mathrm{~W}\right)$ & Rutin & {$[34]$} \\
\hline $\begin{array}{l}\text { Ispanak, fesleğen, } \\
\text { dereotu, salatalık kabuğu }\end{array}$ & & Tartarik Asit & $1: 1$ & $\mathrm{GE}\left(95^{\circ} \mathrm{C}, 2 \mathrm{sa}.\right)$ & Manganez & {$[35]$} \\
\hline $\begin{array}{l}\text { Ispanak, fesleğen, } \\
\text { dereotu, salatalık kabuğu }\end{array}$ & & Oksalik Asit & $1: 1$ & $\mathrm{GE}\left(95^{\circ} \mathrm{C}, 2\right.$ sa. $)$ & Manganez & {$[35]$} \\
\hline $\begin{array}{l}\text { Ispanak, fesleğen, } \\
\text { dereotu, salatalık kabuğu }\end{array}$ & & Sitrik asit & $1: 1$ & GE $\left(95^{\circ} \mathrm{C}, 2\right.$ sa. $)$ & Manganez & {$[35]$} \\
\hline Vanilya baklası & & Sitrik asit:su & $1: 1: 6$ & $\mathrm{GE}\left(50^{\circ} \mathrm{C}, 1 \mathrm{sa}.\right)$ & Vanilya & {$[36]$} \\
\hline Vanilya baklası & & Malik asit:su & $1: 1: 6$ & $\mathrm{GE}\left(50^{\circ} \mathrm{C}, 1\right.$ sa. $)$ & Vanilya & [36] \\
\hline Japon soforası & \multirow{4}{*}{$\begin{array}{l}\text { Sitrik } \\
\text { Asit }\end{array}$} & D-(+)-Glikoz & $5: 3$ & $\operatorname{UDE}\left(20^{\circ} \mathrm{C}, 45 \mathrm{dk} ., 330-450 \mathrm{~W}\right)$ & $\begin{array}{l}\text { Kuersetin, kaempferol, } \\
\text { isorhamnetin }\end{array}$ & {$[37]$} \\
\hline Japon soforası & & D-(+)-Glikoz & $1: 1$ & $\operatorname{UDE}\left(20^{\circ} \mathrm{C}, 45 \mathrm{dk} ., 330-450 \mathrm{~W}\right)$ & $\begin{array}{l}\text { Kuersetin, kaempferol, } \\
\text { isorhamnetin }\end{array}$ & [37] \\
\hline Kerkede & & Gliserol & $1: 4$ & $\operatorname{MDE}(180 \mathrm{~s}, 550 \mathrm{~W})$ & $\begin{array}{l}\text { Fenolik bileşik, } \\
\text { antosiyanin }\end{array}$ & {$[38]$} \\
\hline Kerkede & & Etilen glikol & $1: 4$ & $\operatorname{MDE}(180 \mathrm{~s}, 550 \mathrm{~W})$ & $\begin{array}{l}\text { Fenolik bileşik, } \\
\text { antosiyanin }\end{array}$ & {$[38]$} \\
\hline Japon soforas1 & L-prolin & Adonitol & $1: 1$ & $\operatorname{UDE}\left(20{ }^{\circ} \mathrm{C}, 45 \mathrm{dk} ., 330-450 \mathrm{~W}\right)$ & $\begin{array}{l}\text { Kuersetin, kaempferol, } \\
\text { isorhamnetin }\end{array}$ & {$[37]$} \\
\hline Japon soforas1 & \multirow{3}{*}{ Betain } & $\begin{array}{l}\text { DL-Maleik } \\
\text { asit }\end{array}$ & $1: 1$ & $\operatorname{UDE}\left(20^{\circ} \mathrm{C}, 45 \mathrm{dk} ., 330-450 \mathrm{~W}\right)$ & $\begin{array}{l}\text { Kuersetin, kaempferol, } \\
\text { isorhamnetin }\end{array}$ & {$[37]$} \\
\hline Vanilya baklası & & Sükroz:su & $2: 1: 6$ & $\mathrm{GE}\left(50^{\circ} \mathrm{C}, 1 \mathrm{sa}.\right)$ & Vanilya & {$[36]$} \\
\hline Vanilya baklası & & Sitrik asit:su & $1: 1: 6$ & $\mathrm{GE}\left(50^{\circ} \mathrm{C}, 1\right.$ sa. $)$ & Vanilya & {$[36]$} \\
\hline Bezelye kökleri & \multirow{2}{*}{ Glikoz } & L-prolin & $1: 1$ & $\operatorname{MDE}\left(80^{\circ} \mathrm{C}, 11 \mathrm{dk} ., 600 \mathrm{~W}\right)$ & $\begin{array}{l}\text { Genistin, genistein, } \\
\text { apigenin }\end{array}$ & {$[32]$} \\
\hline Bezelye kökleri & & Laktik asit & $1: 1$ & $\operatorname{MDE}\left(80^{\circ} \mathrm{C}, 11 \mathrm{dk} ., 600 \mathrm{~W}\right)$ & $\begin{array}{l}\text { Genistin, genistein, } \\
\text { apigenin }\end{array}$ & {$[32]$} \\
\hline Vanilya baklası & $\begin{array}{l}\text { Laktik } \\
\text { asit }\end{array}$ & $\begin{array}{c}1,2 \\
\text { Propandiol }\end{array}$ & $1: 1$ & $\mathrm{GE}\left(50{ }^{\circ} \mathrm{C}, 1 \mathrm{sa}.\right)$ & Vanilya & {$[36]$} \\
\hline
\end{tabular}

*GE: Geleneksel Ekstraksiyon; MDE: Mikrodalga Destekli Ekstraksiyon; UDE: Ultrason Destekli Ekstraksiyon

$30{ }^{\circ} \mathrm{C}$ olması durumunda, en düşük değerini aldığ görülmüştür. Bunun nedeni, düşük sıcaklıkta viskozitenin yüksek olmasından dolayı, kütle transferini sınırlandırmasıdır. En yüksek ekstraksiyon verimi, sıcaklık $40{ }^{\circ} \mathrm{C}$ olduğu durumda elde edilmiş olup, bu sicaklığın üzerine çıkıldığında da ekstraksiyon dengelendiği için, verim artışı görülmediği rapor edilmiştir. Derin ötektik çözücü olarak L-karnitin ve 1,3 bütandiol karışımının kullanıldığı başka bir çalışmada ise zencefil tozundan gingeroller, ultrason destekli ekstraksiyon yöntemi ile ekstrakte edilmiştir. Ekstraksiyon işleminde sıcaklık 20, 30, 40, 50 ve $60{ }^{\circ} \mathrm{C}$ olarak değiştirilmiştir. Sıcaklık $20{ }^{\circ} \mathrm{C}$ 'den $50{ }^{\circ} \mathrm{C}$ 'ye çıkarıldığında, artan sıcaklığa bağlı olarak viskozitenin azalması ile ekstraksiyon veriminin arttığı görülmüştür. Ancak, sıcaklık $50{ }^{\circ} \mathrm{C}$ 'den $60{ }^{\circ} \mathrm{C}^{\prime}$ ye çıkarıldığında ekstraksiyon verimi azalmıştır. Bunun nedeninin ise artan 
sicaklık ile birlikte gingerollerin degradasyona uğramasından kaynaklı olduğu bildirilmiştir [45].

Ekstraksiyon üzerine diğer bir önemli faktör ise derin ötektik çözücüyü oluşturan bileşiklerin molar oranları olmuştur. Li vd. [46], yeşil çay yaprakları ile yapmış oldukları çalışmada, materyalden kateşin ekstrakte edebilmek için, kolin klorür:laktik asit ile farklı oranlarda $(1: 1,1: 2,1: 3,1: 4)$ oluşturulan derin ötektik çözücüler hazırlamışlardır. Kolin klorür:laktik asit oranı 1:1'den 1:2'ye çıkarıldığında ekstraksiyon verimin arttığ 1 , ancak bu molar oranın 1:2'den 1:4'e çıkarılmasıyla ekstraksiyon veriminin azaldığı görülmüştür. Bu sonuçlara göre, laktik asit oranın artmasına bağlı olarak azalan viskozitenin kütle transferini arttırarak ekstraksiyon verimliliğini arttırdığı bildirilmiştir. Bunun yanında laktik asit miktarının daha fazla artmasının verimi azaltması ise kolin klorür oranın azalması ile yani hidrojen bağ reseptörlerinin oranın azalması ile açıklanmıştır. Benzer olarak, yeşil çaydan kateşinlerin ekstraksiyonu için kolin klorür ve etilen glikol ile hazırlanan derin ötektik çözücüde etilen glikol oranın arttırılması ekstraksiyon verimini belli bir noktaya kadar arttırabilmiştir [43].

Ekstraksiyon işleminde çözücünün vizkozitesi, kütle aktarımı ve prosesin verimliliği açısından önemli bir parametredir. Derin ötektik çözücülerin viskozitesinin yüksek olması sebebiyle büyük ölçekte akışla ilgili problemlere sebep olabileceği düşünülmektedir. Yüksek vizkoziteye sahip bazı ötektik çözücülerin, kütle transferini azaltabileceği tespit edilmiştir. Bunun çözümü olarak, ekstraksiyonun yapıldığı sıcaklığın arttırılması ve/veya derin ötektik çözücünün belli oranda hidrojen bağ donörü özelliği taşıyan su ile karıştırılması önerilmektedir [26]. Derin ötektik çözücülerin su ile seyreltilerek kullanımının ekstraksiyon verimin arttırdığını gösteren çalışmalar rapor edilmiştir. Cui vd. [32], yapmış oldukları ekstraksiyon işleminde kolin klorür ve 1,6 hekzandiol ile oluşturdukları derin ötektik çözücü içine farklı oranlarda (\%0-90) su ekleyerek çözeltiler oluşturmuştur ve en yüksek ekstraksiyon veriminin \%30 oranında su eklenmesiyle elde ettiklerini bildirmişlerdir. Peng vd. [31], yapmış oldukları çalışmada ise kolin klorür ve 1,3 bütandiol ile oluşturdukları derin ötektik çözücü içine, \%10 su eklediklerinde ekstraksiyon veriminin arttığını belirtmişlerdir. Zhang ve Wang [47], ise diğer çalışmalara paralel olarak, kolin klorür ve 1,4 bütandiol ile hazırlamış oldukları derin ötektik çözücü içine farklı oranlarda (\%0-50) su eklemişler ve en yüksek ekstraksiyon verimine, $\% 30$ oranında su eklenen karışım ile ulaşıldığını belirtmişlerdir.

\section{Sonuçlar}

Yeşil çözücüler, toksik olmayan, geri dönüşümü mümkün olabilen, uçucu olmayan ve sentezi için yüksek maliyet gerektirmeyen çözücülerdir. Sürdürülebilir döngü için, kullanılan zararlı çözücülerin yerine, yeşil çözücü kullanımı desteklenmesi gerekmektedir. Derin ötektik çözücüler, son yıllarda bu amaç ile kullanılan yeşil çözücülerdendir. Derin ötektik çözücüler, sentezlerinin daha kolay olması, daha kararlı olmaları, biyo-bozunur olmaları ve düşük toksisiteye sahip olmaları gibi özellikleri nedeniyle ekstraksiyon proseslerinde aranan çözücü haline gelmişlerdir. Ekstraksiyonun yanı sıra, derin ötektik çözücüler, nanoteknoloji, biyoteknoloji, polimerizasyonlar, biyokütle işleme, malzeme hazırlama, biyodizel sentezi, enzim katalizli reaksiyonlar, karbon dioksit adsorpsiyonu, elektrokimya ve organik sentez gibi çeşitli araştırma alanlarında da kendine kullanım alanı bulmuştur.

\section{Çıkar çatışması}

Yazarların başka kişiler ve/veya kurumlar ile çıkar çatışması bulunmamaktadır.

\section{Benzerlik oranı (iThenticate): $\% 6$}

\section{Kaynaklar}

[1] P. T. Anastas, and J. C. Warner, Green chemistry: Theory and Practice. Oxford University Press Oxford. 1998.

[2] M. Poliakoff, and P. Licence, Green chemistry, Nature, vol. 450(6), 810-812, 2007. https://doi.org/10.1038/ 450810a.

[3] Y. Marcus, Deep eutectic solvents. Chapter 1: Introduction. Springer Nature Switzerland AG, ISBN: 9783030006075, 2019.

[4] L. S. Torres-Valenzuela, A. Ballesteros-Gómez, and S. Rubio, Green solvents for the extraction of high addedvalue compounds from agri-food waste. Food Engineering Reviews, 12, 83-100, 2020. https://doi. org/10.1007/s12393-019-09206-y.

[5] Y. Marcus, Solvent mixtures. Properties and preferential solvation. M. Dekker, New York, ISBN 9780824708375, 2002.

[6] A. Loppinet-Serani, C. Aymonier, and F. Cansell, Current and foreseeable applications of süper- critical water for energy and the environment.Chemistry and Sustainability, Emergy and Materials, 1(6), 486-503, 2008. https://doi:10.1002/cssc.200700167.

[7] Y. Marcus, Supercritical water. Chapter 1:Introduction. Wiley, New York, ISBN: 9780470889473, 2012.

[8] S. P. M. Ventura, F. A. de Silva, M. V. Quental, D. Mondal, M. G. Freire, and J. A. P. Coutinho, Ionicliquid mediated extraction and separation processes for bioactive compounds: past, present, and future trends. Chemical Reviews, 117, 6984-7052, 2017. https://doi. org/10.1021/acs.chemrev.6b00550.

[9] P. Dominguez de Maria, Ionic liquids, switchable solvents and eutectic mixtures. In: Green solvents. Elsevier, Amsterdam, p. 533, 2017.

[10] H. Passos, M. G. Freire, and J. A. P. Coutinho, Ionic liquid solutions as extractive solvents for value-added compounds from biomass. Green Chemistry, 16, 47864815, 2014. https://doi.org/10.1039/C4GC00236A.

[11] E. L. Smith, A. P. Abbott, and K. S. Ryder, Deep eutectic solvents (DESs) and their applications. Chemical Reviews, 114, 11060-11082, 2014. https:// doi.org/10.1021/cr300162p.

[12] D. J. G. P. van Osch, L. F. Zubeir, A. van den Bruinhorst, M. A. A. Rocha, and M. C. Kroon, Hydrophobic deep eutectic solvents as water 
immiscible extractants. Green Chemistry, 17(9), 45184521, 2015. https://doi.org/10.1039/C5GC0 1451D.

[13] B. D. Ribeiro, C. Florindo, L. C. Iff, M. A. Z. Coelho, and I. M. Marrucho, Menthol-based eutectic mixtures: hydrophobic low viscosity solvents. ACS Sustainable Chemistry \& Engineering, 3(10), 2469-2477, 2015. https://doi. org/10.1021/acssuschemeng.5b00532.

[14] Z. Maugeri, and P. Dominguez de Maria, Novel choline-chloride-based Deep eutectic solvents with renewable hydrogen bond donors: levulinic acid and sugar-based polyols. RSC Advances, 2(2), 421-425, 2012. https://doi.org/10.1039/C1RA00630D.

[15] C. Florindo, F. S. Oliveira, L. P. N. Rebelo, A. M. Fernandes, and I. M. Marrucho, Insights into the synthesis and properties of deep eutectic solvents based on cholinium chloride and carboxylic acids. ACS Sustainable Chemistry\&Engineering, 2,2416-2425, 2014. https://doi.org/10.1021/sc500439w.

[16] G. Garcia, M. Atilhan, and S. Aparicio, An approach for the rationalization of melting temperature for deep eutectic solvents from DFT. Chemical Physics Letters, 634, 151-155, 2015. https://doi.org/10.1016/j.cplett. 2015.06.017.

[17] A. P. Abbott, G. Capper, D. L. Davies, R. K. Rasheed, and V. Tambyrajah, Novel solvent properties of choline chloride/urea mixtures. Chemical Communications, 1 , 70-71, 2003. https://doi.org/10.1039/B210714G.

[18] A. P. Abbott, P. M. Cullis, M. J. Gibson, R. C. Harris, and E. Raven, Extraction of glycerol from biodiesel into a eutectic based ionic liquid. Green Chemistry, 9, 868-872, 2007. https://doi.org/10. 1039/B702833D.

[19] L. F. Zubeir, M. H. M. Lacroix, and M. C. Kroon, Low transition temperature mixtures as innovative and sustainable $\mathrm{CO}_{2}$ capture solvents. The Journal of Physical Chemistry B, 118, 14429-14441, 2014. https://doi.org/10.1021/jp5089004.

[20] G. Garcia, S. Aparicio, R. Ullah, and M. Atilhan, Deep eutectic solvents: physicochemical properties and gas separation applications. Energy Fuels, 29, 2616-2644, 2015. doi.org/10.1021/ef5028873.

[21] J. Dai, and R. J. Mumper, Plant phenolics: extraction, analysis and their antioxidant and anticancer properties. Molecules, 15(10), 7313-7352, 2010. https://doi:10. 3390/molecules15107313.

[22] M. S. Jesus, L. F. Ballesteros, R. N. Pereira, Z. Genisheva, A. S. Carvalho, C. Pereira-Wilson, J. A. Teixeira, and L. Domingues, Ohmic heating polyphenolic extracts from vine pruning residue with enhanced biological activity. Food Chemistry, 2020, https://doi:10.1016/j.foodchem.2020.126298.

[23] I. Ignat, I. Volf, and V. I. Popa, A critical review of methods for characterization of polyphenolic compounds in fruits and vegetables. Food Chemistry, 126(4), 1821-1835, 2011. https://doi.org/10.1016/j. foodchem.2010.12.026.

[24] L. Duan, L. L. Dou, L. Guo, P. Li, and E. H. Liu, Comprehensive evaluation of deep eutectic solvents in extraction of bioactive natural products. ACS Sustainable Chemistry \& Engineering, 4(4), 2405-
2411, 2016. https://doi.org/10.1021/acssuschemeng. $6 b 00091$.

[25] Z. Meng, Z. Jing, D. Hongxia, G. Yuanyuan, and Z. Longshan, Green and efficient extraction of four bioactive flavonoids from Pollen Typhae by ultrasound-assisted deep eutectic solvents extraction. Journal of Pharmaceutical and Biomedical Analysis, 161, 246-253, 2018. https://doi:10.1016/j.jpba.2018. 08.048 .

[26] M. H. Zainal-Abidin, M. Hayyan, A. Hayyan, and N. S. Jayakumar, New horizons in the extraction of bioactive compounds using deep eutectic solvents: A review. Analytica Chimica Acta, 979, 1-23, 2017. https://doi .org/10.1016/j.aca.2017.05.012.

[27] M. C. Cvjetko-Bubalo, N. Ćurko, M. Tomašević, K.Kovačević Ganić, and I. Radojčić Redovniković, Green extraction of grape skin phenolics by using deep eutectic solvents. Food Chemistry, 200, 159-166, 2016.doi.org/10.1016/j.foodchem.2016.01.040.

[28] N. Altunay, A. Elik, and R. Gürkan, Preparation and application of alcohol based deep eutectic solvents for extraction of curcumin in food samples prior toits spectrophotometric determination. Food Chemistry, 2019. https://doi: 10.1016/j.foodchem.2019. 125933.

[29] A. R. Mansur, N. E. Song, H. Won Jang, T. G. Lim, M. Yoo, and T. Gyu Nam, Optimizing the ultrasoundassisted deep eutectic solvent extraction of flavonoids in common buckwheat sprouts. Food Chemistry, 2019. https://doi:10.1016/j.foodchem.2019.05. 003.

[30] A. Garcia, E. Rodríguez-Juan, G. RodríguezGutiérrez, J. J. Rios, and J. Fernández-Bolaños, Extraction of phenolic compounds from virgin olive oil b deep eutectic solvents (DESs). Food Chemistry, 197, 554 561, 2016. https://doi:10.1016/j.food chem.2015.10.13.

[31] X. Peng, M. H. Duan, X. H. Yao, Y. H. Zhang, C. J. Zhao, Y. G. Zu, and Y. J. Fu, Green extraction of five target phenolic acids from Lonicerae japonicae Flos with deep eutectic solvent. Separation and Purification Technology, 157, 249-257, 2016. https://doi.org/10. 1016/j.seppur.2015.10.065.

[32] Q. Cui, X. Peng, X. H. Yao, Z. F. Wei, M. Luo, W. Wang, C. J. Zhao, Y. J. Fu, and Y. G. Zu, Deep eutectic solvent-based microwave-assisted extraction of genistin, genistein and apigenin from pigeon pea roots. Separation and Purification Technology, 150, 63-72, 2015. https://doi.org/10. 1016 /j. seppur.2015.06.026.

[33] B. Xia, D. Yan, Y. Bai, J. Xie, Y. Cao, D. Liao, and L. Lin, Determination of phenolic acids in Prunella vulgaris L.: a safe and green extraction method using alcohol-based deep eutectic solvents. Analytical Methods, 7(21), 9354-9364, 2015. https://doi.org/10. 1039/C5AY02035B.

[34] Y. Huang, F. Feng, J. Jiang, Y. Qiao, T. Wu, J. Voglmeir, and Z. G. Chen, Green and efficient extraction of rutin from Tartary buckwheat hull by using natural deep eutectic solvents. Food Chemistry, 221, 1400-1405, 2017. https://doi.org/10.1016/j. foodchem.2016.11.013. 
[35] E. Bağda, H. Altundağ, and M. Soylak, Highly simple deep eutectic solvent extraction of manganese in vegetable samples prior to its ICP-OES analysis. Biological Trace Element Research, 179(2), 334-339, 2017. https://doi.org/10.1007/ s12011-017-0967-5.

[36] C. G. González, N. R. Mustafa, E. G. Wilson, R. Verpoorte, and Y. H. Choi, Application of natural deep eutectic solvents for the green extraction of vanillin from vanilla pods. Flavour and Fragrance Journal, 33(1), 91-96, 2017. https://doi.org/10.1002 /ffj.3425.

[37] M. W. Nam, J. Zhao, M. S. Lee, J. H. Jeong, and J. Lee, Enhanced extraction of bioactive naturalproducts using tailor-made deep eutectic solvents: application to flavonoid extraction from Flos sophorae. Green Chemistry, 17(3), 1718-1727, 2015. https://doi.org/10. 1039/C4GC01556H.

[38] E. Kurtulbaş, A. G. Pekel, M. Bilgin, D. P. Makris, and S. Şahin, Citric acid-based deep eutectic solvent for the anthocyanin recovery from Hibiscus sabdariffa through microwave-assisted extraction. Biomass Conversion and Biorefinery, 2020. https://doi:10.1007/s13399020-00606-3.

[39] M. Wang, J. Wang, Y. Zhou, M. Zhang, Q. Xia, W. Bi, and D. D. Y. Chen, Ecofriendly mechano-chemical extraction of bioactive compounds from plants with deep eutectic solvents. ACS Sustainable Chemistry \& Engineering, 5(7), 6297-6303, 2017. https://doi.org/ 10.1021/acssuschemeng.7b01378.

[40] Y. L. Kua, and S. Gan, Natural deep eutectic solvent (NADES) as a greener alternative for the extraction of hydrophilic (polar) and lipophilic (non-polar) phytonutrients. Key Engineering Materials, 797, 2028, 2019. https://doi.org/10.4028/www.scientific.net/ KEM.797.20.

[41] S. C. Cunha, and J. O. Fernandes, Extraction techniques with deep eutectic solvents. TrAC Trens in Analytical
Chemistry, 105, 225-239, 2018. https://doi.org/10. 1016/j.trac.2018.05.001.

[42] T. Bosiljkov, F. Dujmić, M. Cvjetko Bubalo, J. Hribar, R. Vidrih, M. Brnčić, E. Zlatic, I. R. Redovniković, and S. Jokić, Natural deep eutectic solvents and ultrasoundassisted extraction: Green approaches for extraction of wine lees anthocyanins. Food and Bioproducts Processing, 102, 195-203, 2017. https://doi.org/10. 1016/j. fbp.2016.12.005.

[43] H. Zhang, B. Tang, and K. Row, Extraction of catechin compounds from green tea with a new green solvent. Chemical Research in Chinese Universities, 30(1), 3741, 2014. https://doi:10.1007/s40242-014-3339-0.

[44] P. Zhou, X. Wang, P. Liu, J. Huang, C. Wang, M. Pan, and Z. Kuang, Enhanced phenolic compounds extraction from Morus alba L. leaves by deep eutectic solvents combined with ultrasonic-assisted extraction. Industrial Crops and Products, 120, 147-154,2018. https://doi.org/10.1016/j.indcrop.2018.04.071.

[45] Y. H. Hsieh, Y. Li, Z. Pan, Z. Chen, J. Lu, J. Yuan, Z. Zhu, and J. Zhang, Ultrasonication-assisted synthesis of alcohol-based deep eutectic solvents for extraction of active compounds from ginger. Ultrasonics Sonochemistry, 2019. https://doi.org/10.1016/j. ultsonch.2019.104915.

[46] J. Li, Z. Han, Y. Zou, and B. Yu, Efficient extraction of major catechins in Camellia sinensis leaves using green choline chloride-based deep eutectic solvents. RSC Advances, 5(114), 93937-93944, 2015. doi.org/10. 1039/C5RA15830C.

[47] L. Zhang, and M. Wang, Optimization of deep eutectic solvent-based ultrasound-assisted extraction of polysaccharides from Dioscorea opposita Thunb. International Journal of Biological Macromolecules, 95, 675-681, 2017. https://doi.org/10.1016/j.ijbiomac. 2016.11.096. 